\title{
ANÁLISIS TERRITORIAL EN ARQUEOLOGÍA: PERCEPCIÓN VISUAL Y ACCESIBILIDAD DEL ENTORNO ${ }^{1}$
}

\section{TERRITORIAL ANALYSES IN ARCHAEOLOGY: VISUAL PERCEPTION AND ACCESSIBILITY OF THE ENVIRONMENT}

\author{
Mar Zamora-Merchán \\ Departamento de Prehistoria y Arqueología, Universidad Autónoma de Madrid. \\ E-mail: mar.zamora@uam.es
}

Presentado el: 30/10/2012 - Aceptado el: 30/07/2013

\begin{abstract}
Resumen
En este artículo continuamos con una línea de trabajo que venimos desarrollando desde hace varios años (véase epígrafe de bibliografía) y que busca mejorar la metodología empleada en la realización de los análisis de visibilidad referidos al entorno de los asentamientos en altura de época iberorromana, metodología que también es aplicable en buena medida a otros períodos y contextos históricos. En concreto, vamos a plantear una aproximación a la visibilidad existente en torno al poblado del Cerro de la Cruz (Almedinilla, Córdoba) que consiste en una valoración cualitativa del área de visibilidad potencial desde el yacimiento menos rígida y parcial de lo habitual en los cálculos de visibilidad al uso. Para ello hemos atendido también al grado de accesibilidad a pie que tienen las zonas no visibles desde el poblado a fin de comprobar si se trata de zonas que, aunque ocultas a la vista, son rápidamente alcanzables por otros medios, lo que restaría cierta importancia práctica a su cualidad de no visible. El análisis de la visibilidad del territorio en arqueología se realiza mediante Sistemas de Información Geográfica (SIG). Aunque en ocasiones se ha considerado al cálculo informático de visibilidad como el mayor avance cualitativo en el estudio de los paisajes de la antigüedad mediante SIG, son numerosos los autores que han reflexionado acerca de los aspectos a mejorar, algunas de cuyas reflexiones recogemos también aquí.
\end{abstract}

Palabras claves: Vsibilidad; Territorio; Viewshed ; Isócronas
Abstract
This paper focuses on viewshed studies in Archaeology. The aim is to contribute to the improvement of the methodological approaches to visibility in Antiquity. Although the examples are based on Iberian Iron Age archaeological sites, the methodology can be applied to other contexts and periods 
too. In particular, viewshed calculation and accessibility map have been overlapped, in order to get an approach less rigid than usual. Viewshed studies in Archaeology are done through Geographic Information Systems (GIS). Although the computerized viewshed has been sometimes considered as the best contribution of GIS to landscape studies, many authors have called attention to several critical points. Some of those ideas are also mentioned here.

Keywords: Viewshed; Territory; Isochrone

"Los guardias diurnos han de ser también veloces para que puedan llegar enseguida y comunicar el mensaje desde la mayor distancia posible, en aquellas circunstancias en

las que no resulte posible transmitir las señales pero sea imprescindible que alguno de ellos lleve el mensaje."

(Aen. Tact. VI,5).

\section{Introducción: visibilidad y territorio}

Para el ser humano, el modo más básico de relacionarse con su entorno es a través del sentido de la vista; la visión permite el impacto más significativo que un lugar produce en nuestros sentidos (Gillings y Wheatley 2001:26). Es también el sentido que en el pasado permitía captar y transmitir información a mayores distancias (comunicación mediante señales visuales). Por ello, es un elemento importante en la articulación de los territorios de la Antigüedad.

\section{Control visual del territorio: definición}

Desde la adopción del bipedismo hasta la consecución de la fotografía de satélite, el control visual del medio terrestre por parte del ser humano ha pasado por diferentes estadios de complejidad en consonancia con las particularidades del contexto geográfico, las necesidades sociopolíticas y el desarrollo tecnológico de los distintos grupos humanos (Zamora 2006a).

El campo visual de un observador aporta a éste información acerca de lo que está ocurriendo en el entorno. En lo que respecta a la visibilidad ejercida desde los asentamientos arqueológicos en la Antigüedad, este campo visual no tiene por qué corresponder con el área de control territorial del yacimiento. Control del territorio y control visual del territorio son dos aspectos diferentes aunque no excluyentes.

En ocasiones, la situación a una mayor altura de un yacimiento con respecto a otro vecino se ha relacionado con un posible significado de dominación del primero sobre el segundo (Keay et al. 2001). Ello está directamente relacionado con el ejercicio de la visibilidad desde una posición elevada, hecho que permite al enclave más alto, además de un status de superioridad simbólica, tener acceso a un mejor control visual sobre el asentamiento situado a menor altura (y también sobre el terreno circundante).

La expresión "control visual" no indica que haya un control político o de cualquier otro tipo sobre el espacio visto, sino que se refiere tan sólo a un control ejercido por el sentido de la vista, como así se percibe en abundantes trabajos en los que se ha utilizado dicha expresión 
(Burillo 1980: 265; Cara y Rodríguez López 1984; Ramos Muñoz y Moreno Araguez 1984; Sáenz de Urturi 1984; García Rincón 1987; Junyent 1991; Stancic 1994: 78; Grau 1998, 2001, 2002b, 2005; Grau y Molina 2005; Allepuz 2001; Baena 2003; Bermúdez 2000, entre otros, aunque en algunos casos no se especifique expresamente).

Sin embargo es posible que el significado intrínseco de la palabra 'control' tenga un mayor impacto en la mente humana que el que tiene la palabra 'visual', y es fácil que su entendimiento tienda a interpretarse en relación con aspectos próximos al control político o territorial, que es algo bien diferente. El control visual es la obtención de información mediante el sentido de la vista acerca de lo que está ocurriendo en el entorno. Esa obtención de información es de vital importancia en momentos de inestabilidad política (como durante los dos siglos de conquista romana de la Península Ibérica).

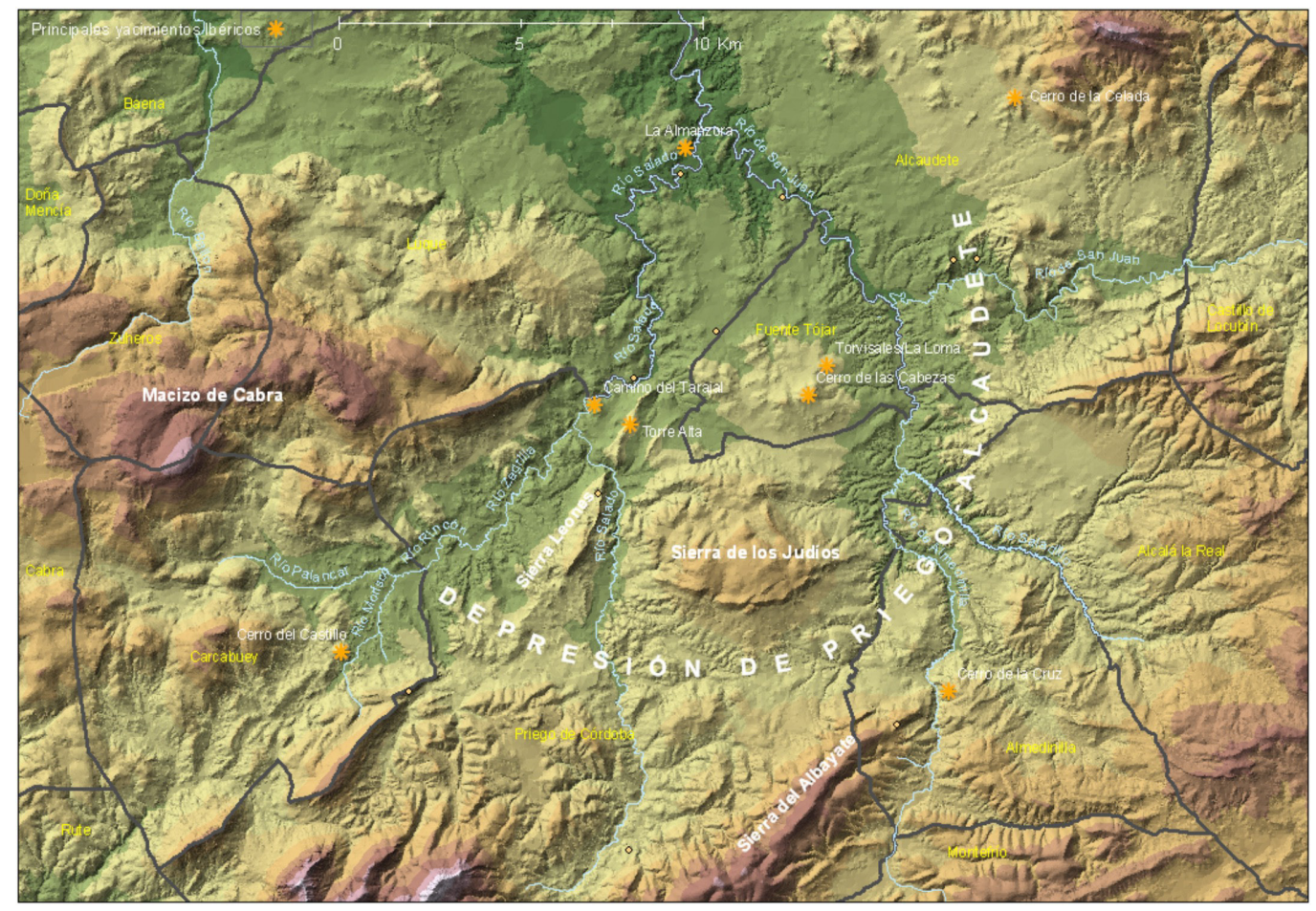

Figura 1. Mapa de la depresión de Priego-Alcaudete con indicación de los yacimientos arqueológicos de época iberorromana más importantes de la zona (Zamora 2010b).

\section{Control visual del territorio: interpretación en Arqueología}

En los estudios arqueológicos, una de las interpretaciones más comunes que se hace de la amplitud y características del campo visual en torno a los asentamientos es la de utilizarlo como dato auxiliar para el establecimiento de una jerarquía entre los distintos asentamientos considerados (Rodríguez Traver y Pérez Ballester 2005: 217).

Habitualmente, considerando un conjunto de asentamientos cercanos entre sí, se suele considerar que el grado de dominio visual sobre el entorno que se disfruta desde cada uno de los yacimientos (medido en base a la extensión del espacio ocupado por 
su cuenca visual teórica) es un criterio más a considerar en la valoración global de las ventajas que presentan sus distintos enclaves: a mayor y mejor control visual mejor emplazamiento.

En la valoración de esas características de visibilidad, además de la ya mencionada amplitud del área visible desde el yacimiento, se presta atención a otros elementos del territorio que posean cierto interés para la vida en el poblado como el control visual sobre las fuentes de recursos de todo tipo o sobre las vías de comunicación y pasos estratégicos.

Pero el control visual no suele ser el único criterio válido a considerar para aproximarse al establecimiento de una jerarquía o funcionalidad entre los distintos yacimientos considerados. Por ello, normalmente se valora conjuntamente con otras variables espaciales como el tamaño del asentamiento, la forma topográfica y/o la proximidad a tierras aptas para el cultivo (Slapšak 1988; Ruíz y Molinos 1993: 117; Novakovic 2001, entre otros muchos estudios).

En concreto, y a modo de ejemplo, mencionamos los trabajos de A. Ruiz en el Alto y Medio-Alto Guadalquivir, en los que se utilizó la amplitud de la visibilidad desde los asentamientos asociada a otras variables (como la potencialidad agraria, entre otras) para establecer una tipología de asentamientos (Ruíz Rodríguez 1990; también en Ruíz et al. 1991: 121, y Ruiz y Molinos 1993: 116). O también Murillo et al. (1989), quienes utilizaron la intervisibilidad de los asentamientos y el "control visual efectivo" de sus "territorios de producción restringida" para valorar el control efectivo del territorio y su defensa "a través de un aparato coercitivo que asegure tanto la propia cohesión del territorio político como la disuasión frente a otros territorios políticos" (Murillo et al. 1989: 167). Y Grau Mira, en el área central de la Contestania Ibérica, realizó un exhaustivo análisis de las condiciones de visibilidad de un buen número de asentamientos fortificados y estableció también una clasificación de oppida en función del grado de dominio visual del territorio entre otros análisis espaciales (Grau 2002a).

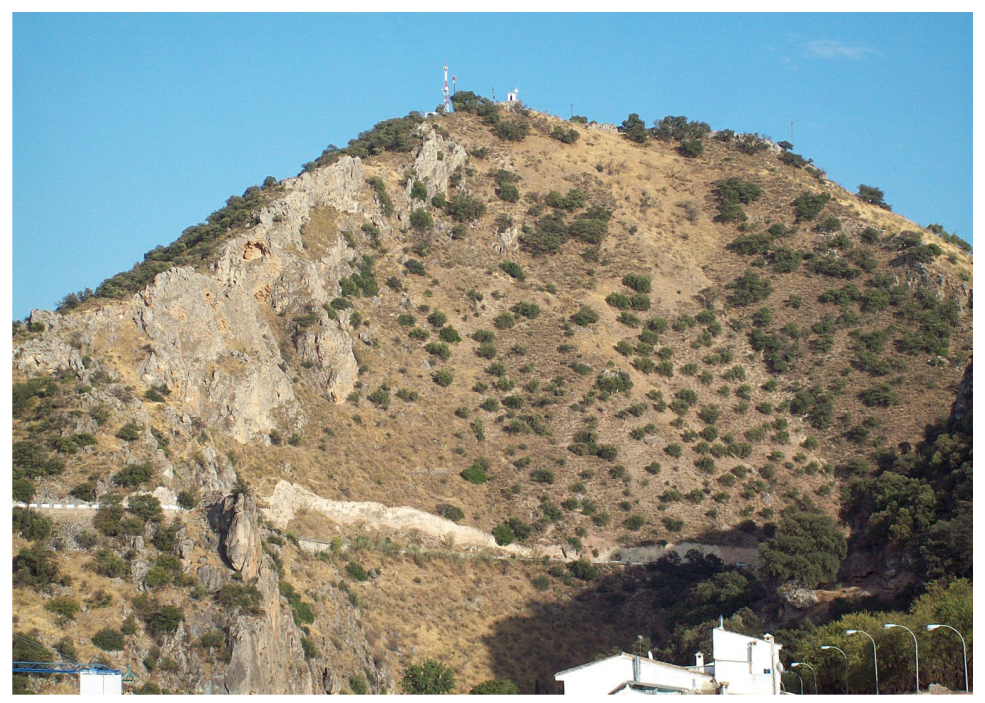

Figura 2. Vista del Cerro de la Cruz, Almedinilla (Córdoba). 


\section{Los Sistemas de Información Geográfica y el estudio de la visibilidad}

Desde hace al menos dos décadas, los estudios de visibilidad del territorio en arqueología se realizan mediante procedimientos informáticos. Los programas SIG (Sistemas de Información Geográfica) permiten calcular la extensión y ubicación del área potencialmente visible desde un determinado punto de observación. Este cálculo recibe en inglés el nombre de viewshed. Gracias a su proliferación dentro de los estudios espaciales en Arqueología, el cálculo informático de visibilidad tiende a ser considerado como el modo en el que más han contribuido los Sistemas de Información Geográfica al estudio del paisaje (idea recogida en Wheatley y Gillings 2000: 1).

Dicho cálculo informático permite analizar, básicamente, dos aspectos:

- la ya mencionada extensión superficial del área visible en torno a un determinado punto de observación (ejemplos en Baena et al. 1995: 114; García Sanjuán 1999, entre otros muchos) y también las características de dicha área (por ejemplo, su nivel de fragmentación, Berrocal 2004);

- conocer si existe intervisibilidad entre dos o más enclaves (Pérez Verbena 2000; Topouzi et al. 2002; Swanson 2003, entre otros).

Gracias a ello, el cálculo informático de visibilidad se ha venido utilizando en Arqueología, entre otros aspectos, para arrojar luz sobre cuestiones tales como la identificación de unidades territoriales (Montilla et al. 1989; Lock y Harris 1996), la conexión

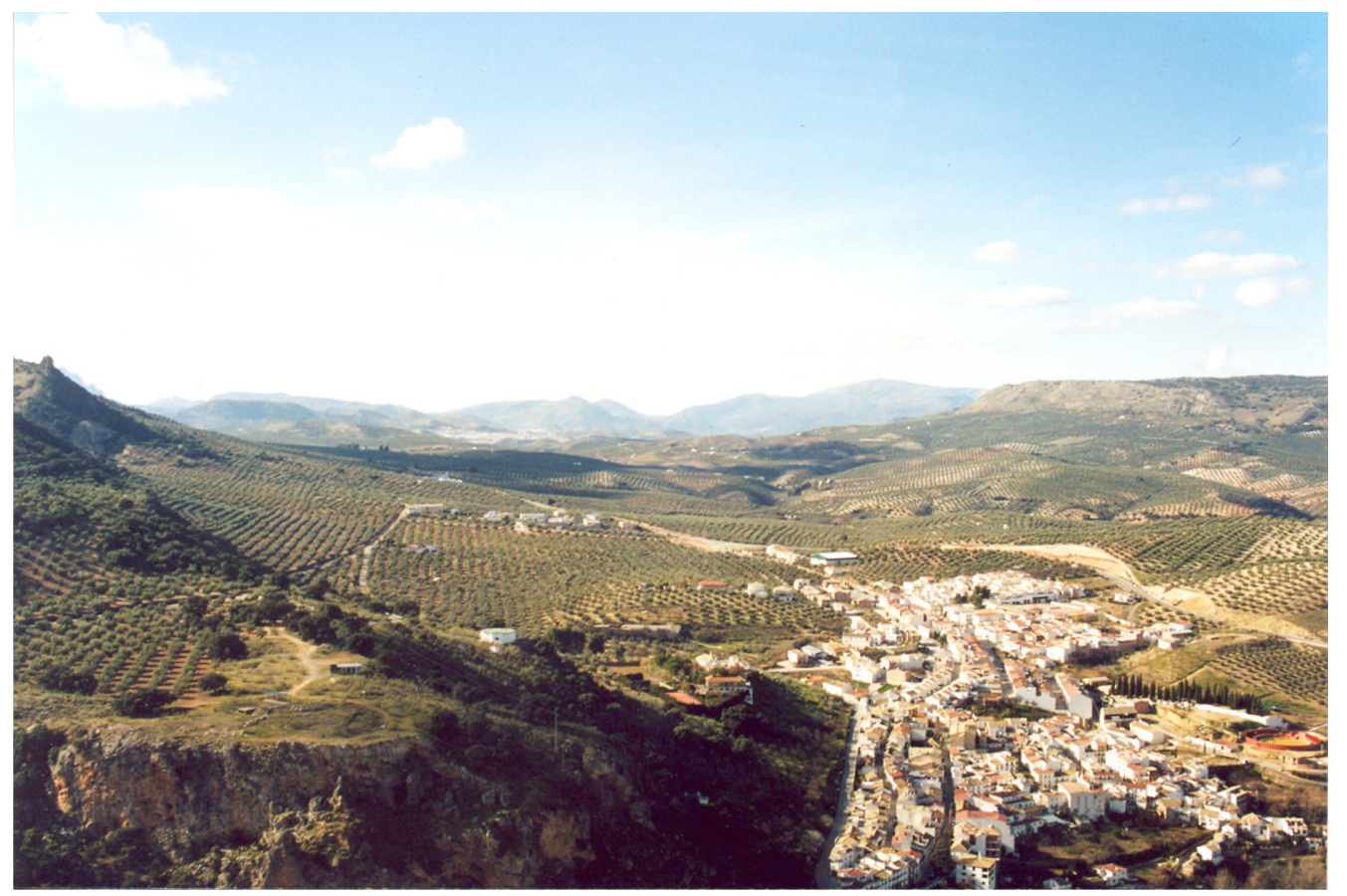

Figura 3. Visibilidad hacia el Oeste desde el Cerro de la Cruz. 
visual entre asentamientos (Grau 1998; Swanson 2003; Ruestes 2006), la defensa del asentamiento (Berrocal Rangel 2004) o la reconstrucción de antiguos suelos de ocupación en la actualidad erosionados (Bell 1999).

La cuantificación de la cuenca visual en relación con su extensión superficial, así como la comprobación de la intervisibilidad de dos o más asentamientos, son análisis que ya estaban presentes en la literatura arqueológica antes de la aparición de los programas SIG, y se llevaban a cabo con la ayuda de cartografía analógica y mediante la observación directa sobre el terreno (Renfrew 1979; Fraser 1983). El análisis informático de la visibilidad paisajística o del territorio, por tanto, en cuanto a su marco teórico se refiere no representa algo nuevo en la disciplina arqueológica (Wheatley y Gillings 2000: 2; Gillings y Wheatley 2001), pero sí ha permitido acercamientos al estudio de la visibilidad del paisaje más amplios, complejos, precisos, elaborados con mucha mayor rapidez y presentados con un lenguaje cartográfico más correcto.

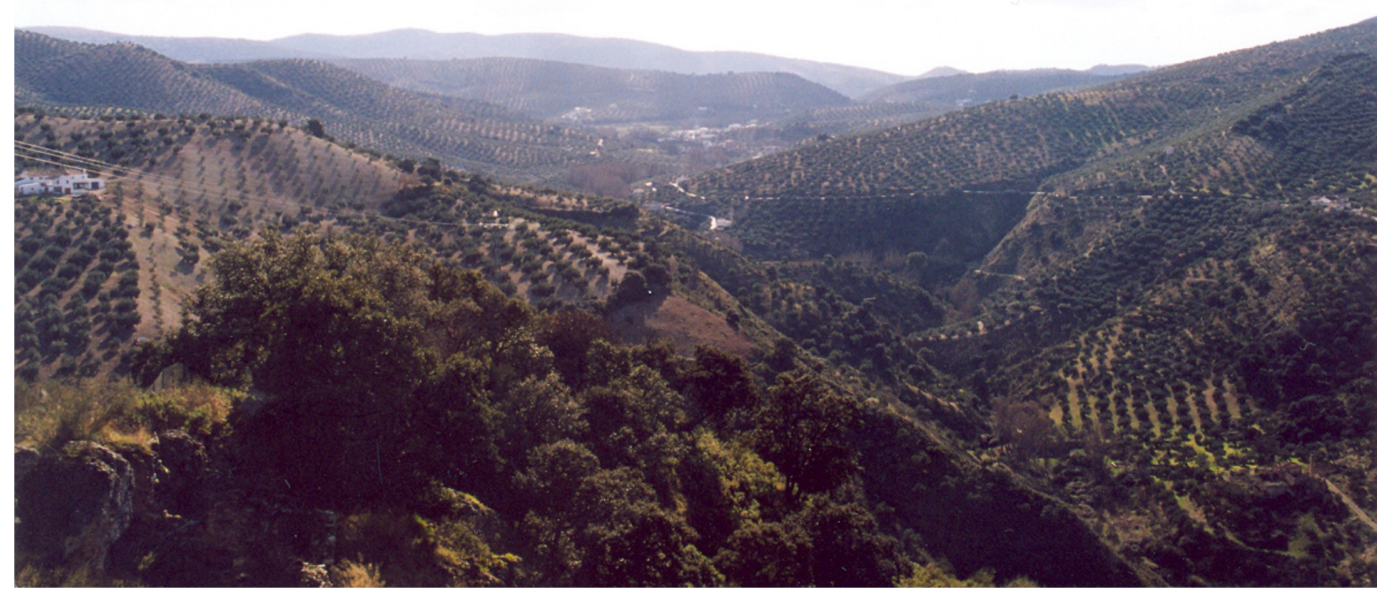

Figura 4. Vista desde el Cerro de la Cruz hacia el Sur.

El modo en el que el programa informático realiza el cálculo del área visible potencial en torno a un determinado punto de observación es el siguiente: dados un Modelo Digital del Terreno (MDT), que reproduce a escala la topografía del área de estudio, y un punto sobre dicho modelo del terreno, que va a actuar como punto de observación, el programa SIG calcula líneas rectas imaginarias desde el punto de observación hasta todos aquellos puntos del MDT que constituyen el primer obstáculo topográfico encontrado en cada dirección, tanto en la vertical como en la horizontal. Aquellas áreas del modelo del terreno que se puedan conectar mediante línea recta con el punto de observación sin que exista ningún elemento topográfico que bloquee dicha línea son clasificados con valor 1, y aquellas áreas que no tengan conexión en línea recta con el observador porque lo impide la topografía 
son clasificadas con valor 0 . El resultado es una superficie binaria (de valores 1 y 0 ) que teóricamente se corresponde con la superficie terrestre visible (1) y no visible (0) desde el lugar elegido como punto de observación (Figura 5).

Este sencillo análisis puede hacerse más rico y complejo mediante la inclusión de diversos parámetros como el radio de alcance de la vista, la altura a la que se sitúa el observador (por ejemplo, sobre una torre), la orientación cardinal del cálculo, así como

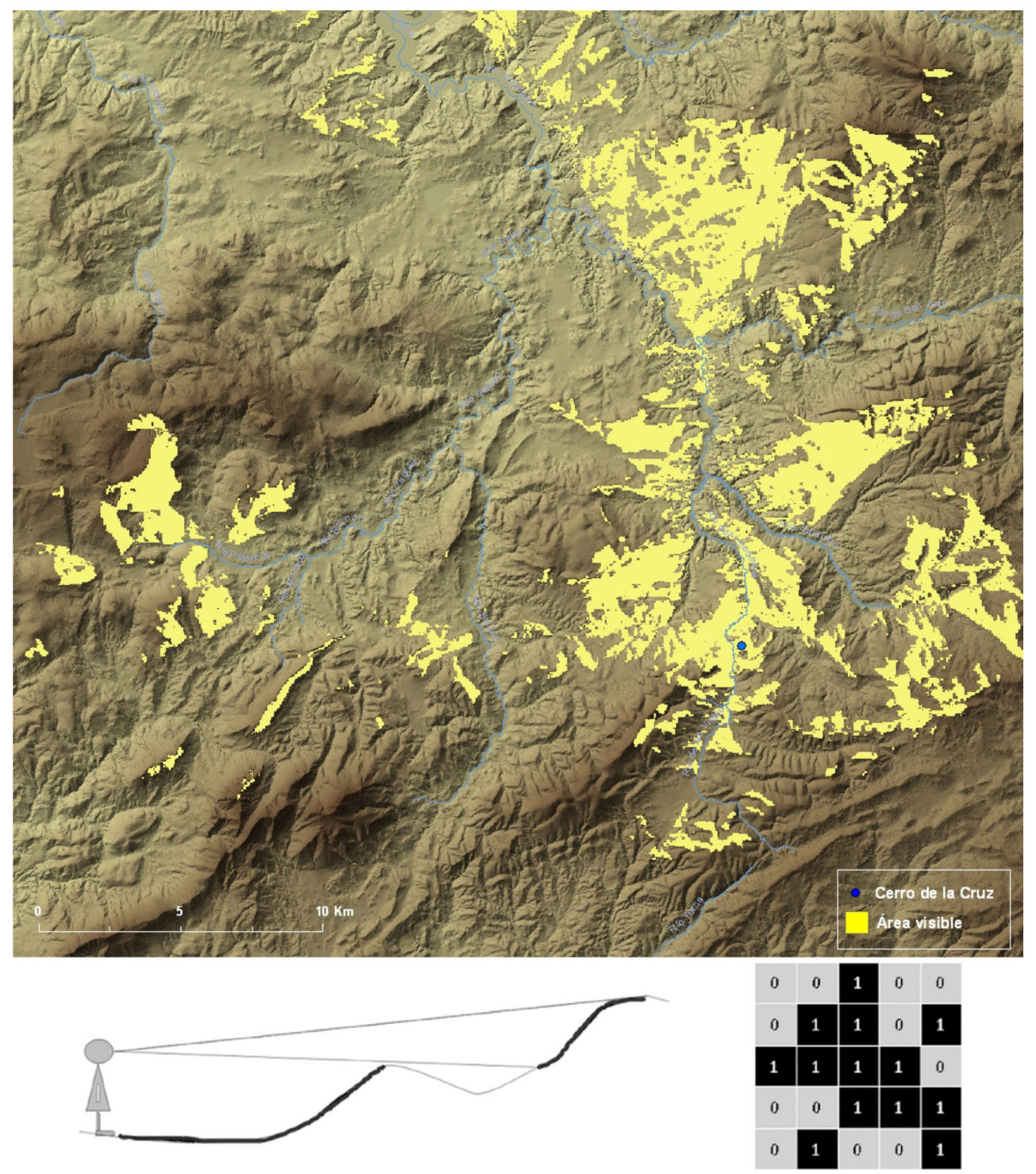

Figura 5. (Arriba) Cálculo de visibilidad desde el Cerro de la Cruz de Almedinilla. Las zonas en color amarillo son las zonas visibles desde el punto de observación. (Abajo) Explicación del cálculo de visibilidad informático: a las zonas visibles por el observador (áreas en color negro) el programa les asigna un valor 1, y a las no visibles un valor 0 . El resultado es una cuadrícula de celdillas con valores 1 (visible) y 0 (no visible), y que se diferencian gráficamente con colores distintos (Zamora 2010b). 
realizar análisis de visibilidad con múltiples observadores a un mismo tiempo, para cuya explicación y comentario bibliográfico de casos remitimos a otros trabajos previos (Zamora 2006a).

Aunque el cálculo de visibilidad se realiza con un algoritmo simple y con equipos informáticos potentes, existen límites en las capacidades de ambos (Felleman 1986: 57). Así, la investigación reciente viene demostrando que, ante unas mismas condiciones de partida, el resultado obtenido del cálculo informático de visibilidad puede ser diferente según se utilice un programa informático u otro, según se utilice un tipo de Modelo Digital del Terreno u otro, o según los valores de los parámetros o la cantidad de parámetros elegidos para realizar el cálculo. Todo esto introduce un alto grado de incertidumbre en el resultado obtenido. En consecuencia, en los trabajos sobre visibilidad que utilizan herramientas SIG, ha sido frecuente encontrar comentarios al respecto de la existencia de estos desajustes, tanto los internos de la propia técnica como los existentes entre técnica y realidad, que lejos de ahuyentar al investigador han contribuido a madurar este tipo de aproximaciones al paisaje desde la fecha de aparición de los $\mathrm{SIG}^{2}$.

\section{Percepción sensorial y SIG: ¿sólo el sentido de la visión?}

La visión de un territorio es un ejercicio sensorial, y por ello su representación y tratamiento no siempre encuentra buen acomodo en el ámbito de la cartografía y la informática. Por ejemplo, al respecto de la percepción del observador en el campo, cuando el área visible en torno al observador se representa sobre un mapa (como hacen los SIG), se distorsiona la perspectiva de la visibilidad real sobre el terreno (Llobera 1996: 613; Wheatley 2000: 126; Zamora 2006a). Determinadas zonas del área visible representada ocupan una superficie mucho mayor sobre el mapa de la que ocupan en la perspectiva de la vista, lo que puede conducir a interpretaciones poco ajustadas a la realidad.

Además, la facilidad que ofrecen los SIG para cuantificar la visibilidad del territorio ha producido un desequilibrio en la literatura al uso en cuanto a la atención prestada al análisis del sentido de la visión en detrimento de otros como el oído o el olfato que han sido muy poco analizados en el contexto de las aplicaciones SIG al estudio del espacio en arqueología y que, sobra decirlo, contribuyen también a percibir lo que está ocurriendo en el territorio. De hecho, los autores de la antigüedad clásica nos han dejado numerosas menciones a la importancia de la complementariedad del resto de sentidos, además del de la vista, para la percepción del medio ${ }^{3}$.

Aunque son todavía muy escasas, existen aproximaciones al estudio de la acústica y el olor del paisaje a través de herramientas SIG. Por ejemplo, cabe mencionar el concepto de audibility sheds también llamadas asheds (Constantinidis 2004), o la propuesta de Tschan et al. (2000: 45) para utilizar la herramienta Line of sight como modo de caracterizar la percepción del oído, la vista y el olfato basándose en que los tres sentidos poseen una componente espacial relacionada con la distancia del punto de emisión del estímulo al punto en el que se encuentra el receptor (Tschan et al. 2000: 45, Fig. 10), planteamiento que posee a su vez sus propias particularidades (usar instrumentos o usar la voz, voces de varios individuos o de uno solo, etc.). 


\section{La importancia de la cartografía digital utilizada}

Algunas otras cuestiones de importancia en el cálculo de visibilidad se refieren a cuestiones técnicas, como por ejemplo, la calidad y resolución de la cartografía utilizada para la creación del modelo digital del terreno y cómo éste es creado (Kvamme 1990; Marozas y Zack 1990, fueron algunos de los primeros que lo mencionaron en el ámbito de la arqueología. Para una bibliografía más extensa véase Zamora 2006a:12).

La incertidumbre contenida en los MDT puede venir causada por deficiencias en el equipamiento, precisión del formato de los datos, interpolación deficiente o incluso errores humanos. El trabajo original de campo, la destreza del cartógrafo que genera el mapa analógico, del que lo digitaliza y lo convierte en MDT, etc., son fuentes potenciales de generación de errores (Walsh et al. 1987; Fisher 1991).

Los más básicos son los siguientes:

- valores de las elevaciones,

- efectos de la rasterización de los modelos de elevaciones,

- errores de interpolación introducidos por la isolínea al algoritmo del MDT, y

- desplazamiento locacional de los asentamientos.

Y estos errores pueden ser propagados en errores secundarios a través de sucesivas operaciones tales como visibilidades individuales, visiblidades acumuladas, etc. (Fisher 1991; Wheatley 1995). Por tanto, para procurar obtener unos buenos resultados en los análisis de visibilidad con SIG es muy importante disponer de una cartografía digital de gran calidad.

El caso de la cartografía española se encuentra en un buen momento, que nos ha llevado incluso a hablar en alguna ocasión de 'revolución' en el acceso a datos cartográficos de calidad (Zamora y Baena 2010). La orden FOM/956/2008, de 31 de marzo, por la que se aprueba la política de difusión pública de la información geográfica generada por la Dirección General del Instituto Geográfico Nacional (IGN), estipula que toda la producción cartográfica digital llevada a cabo por el IGN "tendrá carácter libre y gratuito, siempre que se mencione el origen y propiedad de los datos" y para uso no comercial (BOE 08/04/08).

Desde entonces, para facilitar el acceso a dichos datos, el Centro Nacional de Información Geográfica CNIG, Organismo autónomo dependiente del IGN, viene desarrollando y alimentando la plataforma web de descarga de datos. Ese Centro de descargas del CNIG, alojado en la página web de la Institución, está poniendo a disposición del usuario, para uso no comercial y previo registro telemático, toda la cartografía digital o digitalizada que se produce en el Instituto Geográfico Nacional. Ya son muchas las entradas disponibles para la descarga desde el catálogo de productos on-line (http:/ / centrodedescargas.cnig. es/CentroDescargas/index.jsp).

Están disponibles para descarga on-line entre otros productos la Base Cartográfica Numérica a escala 1:25.000 (BCN25), que contiene en formato shapefile toda la información recogida en la cartografía analógica del Mapa Topográfico Nacional (MTN) a escala 1:25.000; el Modelo Digital del Terreno con paso de malla de 25 m (llamado MDT25), que se presenta 
en formato de archivo ASCII matriz ESRI (agr), obtenido por interpolación de modelos digitales del terreno de $5 \mathrm{~m}$ de paso de malla procedentes del Plan Nacional de Ortofotografía Aérea (PNOA), o las propias ortofotos del PNOA, y también mapas históricos como los de la primera serie del MTN, que están disponibles en formato raster.

Además, la creación de Infraestructuras de Datos Espaciales (IDE) se ha convertido en uno de los retos de cabecera de los institutos y centros de cartografía españoles, tanto del IGN como de los Institutos cartográficos de las distintas Comunidades Autónomas (generadores también de cartografía de calidad, en escalas mayores de 1:25.000). Desde el Instituto Geográfico Nacional se promueve intensamente el desarrollo de la Infraestructura de Datos Espaciales de España (IDEE), que tiene como objetivo "integrar a través de Internet los datos, metadatos, servicios e información de tipo geográfico que se producen en España" integrando en su Geoportal todos los nodos y geoportales de recursos IDE de los productores de datos geográficos nacionales, regionales y locales (IGN, IDEE: http://www.idee.es) .

Todas estas mejoras en la accesibilidad de la información cartográfica digital de calidad han posibilitado un gran avance en los estudios territoriales en Arqueología, y los modelos digitales del terreno de gran precisión (de resolución de $5 \mathrm{~m}$ o incluso menos) auguran un buen futuro a los análisis espaciales con SIG.

\section{La accesibilidad de las zonas del territorio no visibles desde el asentamiento}

Una de las críticas más plausibles al análisis de visibilidad básico es que el hecho de utilizar un punto de observación fijo en el espacio elimina la posibilidad de que el observador potencial se desplace a fin de transmitir una información concreta sobre lo que está ocurriendo en un determinado lugar que aunque cercano no sea visible desde el asentamiento. Los textos de los escritores de la antigüedad clásica nos han dejado abundantes noticias de la combinación del desplazamiento junto con la transmisión de mensajes visuales ${ }^{4}$.

Al igual que en el estudio de la visibilidad del paisaje, en el ámbito de la arqueología se han realizado interesantes trabajos que profundizan y exploran el movimiento del ser humano por el territorio, atendiendo al trazado de rutas óptimas para el desplazamiento, a los caminos y vías pecuarias tradicionales, o al grado de accesibilidad de los enclaves entre otros aspectos (véase, por ejemplo, Llobera et al. 2011; Murrieta-Flores 2012, y la bibliografía adjunta en dichos trabajos).

En este trabajo, planteamos la combinación del análisis de visibilidad con el análisis del desplazamiento por el territorio, a fin de valorar si las zonas no visibles desde el asentamiento son fácilmente accesibles a pie desde el mismo, lo que restaría cierta (o toda) importancia a su cualidad de 'no visible' puesto que podrían ser alcanzadas por un caminante desde el yacimiento en un corto espacio de tiempo.

Considerando el grado de accesibilidad del territorio desde un punto de vista economicista, y tomando un determinado punto de partida, un lugar será más fácilmente accesible cuanto menor tiempo necesite emplear un caminante para llegar hasta él.

El tiempo empleado por el caminante dependerá, entre otros aspectos, del tipo de terreno (en un mismo período de tiempo recorrería una mayor distancia si el terreno fuese llano y una menor distancia si tuviese que desplazarse por un terreno accidentado con pendientes 
pronunciadas). Tomando como punto de partida un asentamiento, si midiésemos el espacio recorrido en 1 hora de tiempo en cada una de las direcciones que es posible tomar en la partida (radios en torno al asentamiento hasta completar los $360^{\circ}$ del círculo), se obtendría un mapa de accesibilidad al sitio en 1 hora de tiempo. A mayor dificultad en el desplazamiento menor sería la distancia recorrida en un período de tiempo equivalente, y el resultado gráfico sería una línea poligonal cerrada que uniría todos los puntos distantes 1 hora caminando desde el punto de partida en línea recta y hacia todas direcciones (una isócrona de distancia). Cuanto más fácil de transitar sea el terreno (cuanto más lejos se pueda llegar desde el yacimiento caminando durante el tiempo establecido) mayor será la superficie comprendida dentro de la isócrona (Figura 6).

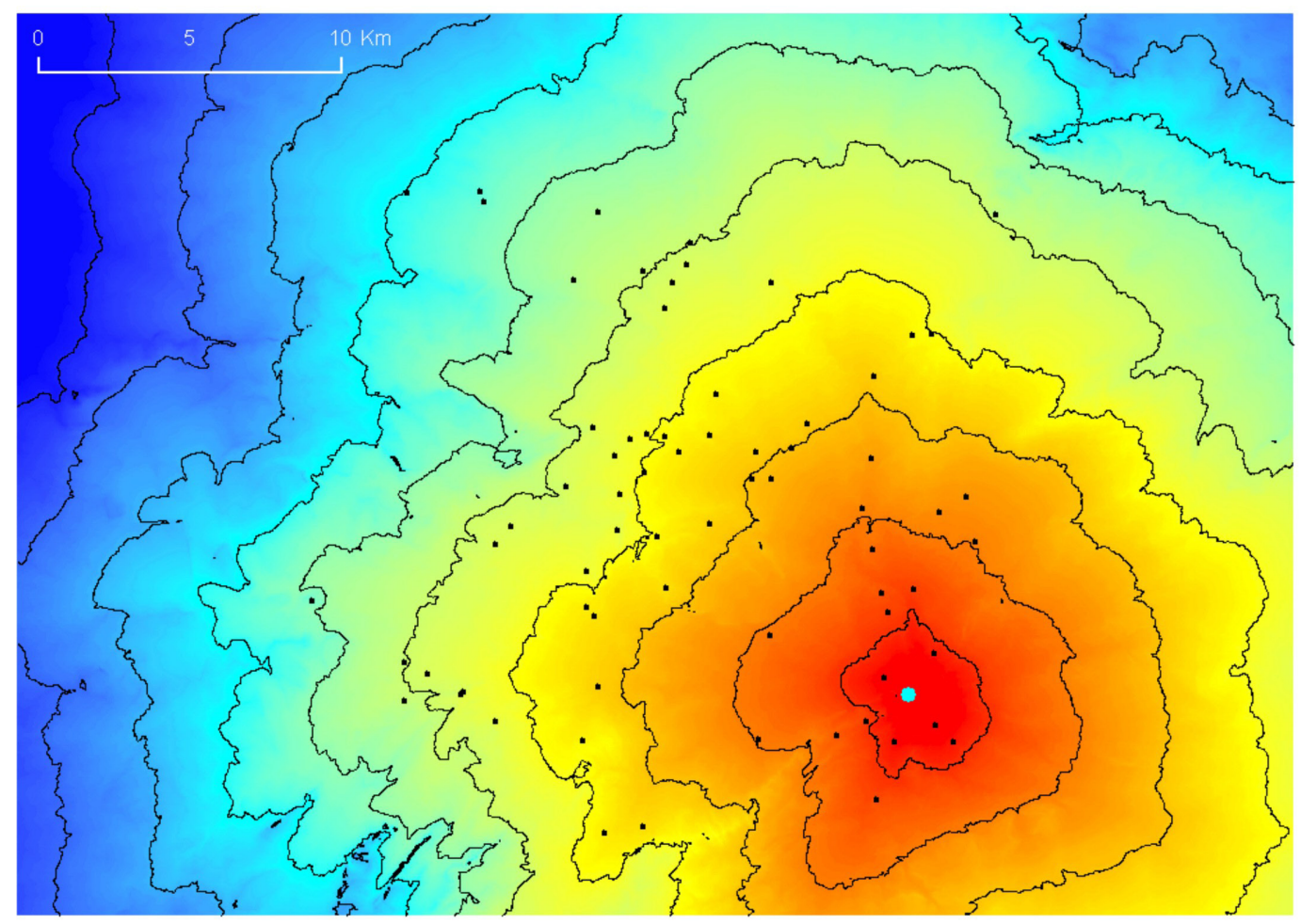

Figura 6. Imagen que muestra varias líneas isocronas de distancia al Cerro de la Cruz (punto azul en la parte inferior derecha de la imagen). La primera línea de color negro en torno al yacimiento se encuentra 1 hora de distancia caminando desde el mismo; la segunda a 2 horas, y así sucesivamente (Zamora 2010b). La coloración de fondo en gradiente del rojo al azul, corresponde con la superficie de coste de desplazamiento generada por el programa SIG.

El estudio de la accesibilidad entraña complejidad tanto en el planteamiento teórico como en la ejecución práctica mediante SIG. Requiere conocer de antemano, por ejemplo, la velocidad a la que se produce el desplazamiento. Esta velocidad es una variable dependiente a su vez de muchos aspectos como la pendiente del terreno, la forma física del caminante, si lleva carga o va ligero, si se desplaza a pie o a caballo, etc. Puesto que las posibles variaciones son numerosas, para poder avanzar en la investigación se opta por elegir parámetros estándar. Por ejemplo, en el campo de la física se han desarrollado diversos algoritmos que establecen velocidades medias de un ser humano en función de la pendiente del terreno por el que se desplaza basándose en experimentos reales. 
Estos algoritmos se han adoptado, y en ocasiones adaptado, en el campo de los estudios arqueológicos del territorio. El usado aquí es el algoritmo de Tobler, que indica la velocidad media de un caminante en función del tipo de terreno (Tobler 1993).

\section{Un ejemplo: el Cerro de la Cruz}

El Cerro de la Cruz de Almedinilla se localiza en el borde sur de la Depresión de PriegoAlcaudete, y aunque estructuralmente no pertenece a la depresión (se trata de una de las elevaciones anticlinales que la enmarcan) sí lo hace desde el punto de vista de su paisaje.

La depresión de Priego-Alcaudete se localiza en el piedemonte oriental de las Sierras Subbéticas, constituyendo la ladera oriental del interfluvio Genil-Guadajoz en la zona del sur de la provincia de Córdoba, y a su vez es parte de la cabecera de este último río (Ortega Alba 1975). Se trata de una depresión compleja y de relieve accidentado, pues a pesar de ser una unidad estructural deprimida (una depresión) presenta varias elevaciones en su interior, y además su litología (fundamentalmente caliza y fácilmente erosionable) ha dado lugar a formas de relieve complejas (Figura 1).

Es también una zona rica en yacimientos arqueológicos desde la Prehistoria a nuestros días. Según los estudios realizados desde 1985 a 2001, durante el ibérico tardío se asiste en la depresión de Priego-Alcaudete a una reorganización del territorio con cierta herencia de la ocupación anterior. Si bien para el período del ibérico pleno sólo conocemos cinco poblados con ocupación, durante el ibérico final parece que coexisten tres tipos de asentamientos:

- asentamientos de gran tamaño y con potentes fortificaciones;

- asentamientos de mediana entidad sin fortificaciones;

- y otros asentamientos de pequeño tamaño (menores de 0,5 Has) como Los Zurriones y Los Llanos de Zamoranos, ambos en el municipio de Priego de Córdoba (Vaquerizo et al. 1991; Vaquerizo et al. 2001).

Esta reorganización se ha interpretado desde varias perspectivas: bien como consecuencia de la presión generada desde las unidades políticas de la campiña de Jaén (Ruíz Rodríguez y Molinos, 1989) y la campiña de Córdoba (Murillo et al., 1989), bien como una ruptura en la relación potencial demográfico/recursos de los propios oppida de la zona o como ambas (Vaquerizo et al. 2001).

En un contexto de reorganización territorial, resulta de gran interés acometer análisis espaciales relativos a la ubicación de los distintos asentamientos. En trabajos previos (Zamora 2010b) presentamos una valoración general del espacio en el que se enmarcan los asentamientos más importantes de la zona. Ahora vamos a plantear una mejor caracterización del área de visibilidad, y utilizaremos como ejemplo el poblado del Cerro de la Cruz.

El Cerro de la Cruz, en el término municipal de Almedinilla (Córdoba), es uno de los yacimientos ibéricos mejor conocidos de la zona (vease Muñiz y Quesada 2010). Se trata de un cerro labrado sobre uno de los pliegues anticlinales perteneciente al conjunto de la unidad de las Subbéticas. Su forma picuda presenta una pendiente más suave por el Sur y el Este (por donde el acceso es posible hasta para jinetes) y fuertemente escarpado en sus vertientes norte y oeste (accesibles sólo a pie), asomándose ésta última abruptamente al cauce 
del río Almedinilla que discurre encajonado entre el cerro de la Cruz y la vecina Sierra del Albayate. Por el flanco N-NO, el cerro resulta fácilmente identificable en la distancia por su característico perfil. Alcanza los $952 \mathrm{~m}$ de altitud, lo que le confiere una posición de atalaya privilegiada sobre la Depresión de Priego-Alcaudete.

\section{Análisis de visibilidad y accesibilidad}

La visibilidad desde el yacimiento es amplia y en algunos puntos alcanza largas distancias. Sin embargo, debido a las abundantes elevaciones del relieve, dicha visibilidad es también irregular, estando bloqueada en algunos sectores a escasos kilómetros del yacimiento (hacia el NO y hacia el SE) (Figura 5).

Como mencionamos al principio de este artículo, vamos a mostrar un análisis de la visibilidad existente en torno al poblado del Cerro de la Cruz (Almedinilla, Córdoba) que consiste en una valoración cualitativa del área de visibilidad potencial desde el yacimiento menos rígida y parcial de lo habitual en los cálculos de visibilidad al uso. Para ello hemos prestado atención también al grado de accesibilidad a pie que tienen las zonas no visibles desde el poblado a fin de comprobar si se trata de zonas que, aunque ocultas a la vista, son rápidamente alcanzables por otros medios, lo que restaría cierta importancia práctica a su cualidad de no visible. En concreto nos hemos centrado en el área inmediata al yacimiento.

La visibilidad del medio circundante desde el yacimiento en el entorno más cercano (en un radio aproximado de $3 \mathrm{~km}$ ) se extiende mayoritariamente desde el Suroeste hasta el Noreste, existiendo un área hacia el Este-Sureste-Sur que queda mayoritariamente oculta a la vista.

Para valorar el grado de accesibilidad a pie de estas zonas ocultas, el procedimiento seguido fue el siguiente (utilizando el programa SIG ArcGIS) ${ }^{6}$ :

En primer lugar, calculamos la visibilidad en torno al yacimiento. Utilizamos como potenciales observadores varios puntos distribuidos sobre la superficie del cerro. La altura a la que se situaría el observador la establecimos en $6 \mathrm{~m}$. La altura del objetivo visual fue de $2 \mathrm{~m}$, y el radio de alcance del cálculo se estableció como ilimitado.

A continuación calculamos isócronas de distancia al yacimiento. Para ello utilizamos como información de partida la pendiente del terreno del MDT combinada con el parámetro de la velocidad de desplazamiento de un caminante según el algoritmo de Tobler para caminar por terrenos montañosos (Tobler 1993). Finalmente utilizamos el comando Path Distance para calcular una superficie de coste de desplazamiento en torno al Cerro de la Cruz que sirvió para calcular isócronas de 15 minutos de distancia al yacimiento (Zamora 2010b, 2012).

Una vez obtenidas las isócronas, las superpusimos al resultado del cálculo de visibilidad (Figura 7). El objetivo era averiguar cómo de accesibles a pie eran las zonas de terreno no visibles desde el yacimiento. Si el resultado era una rápida accesibilidad a estas zonas, ello paliaría en buena medida su condición de 'no visible' a la hora de valorar la importancia de la visibilidad del territorio para la vida en el poblado. 


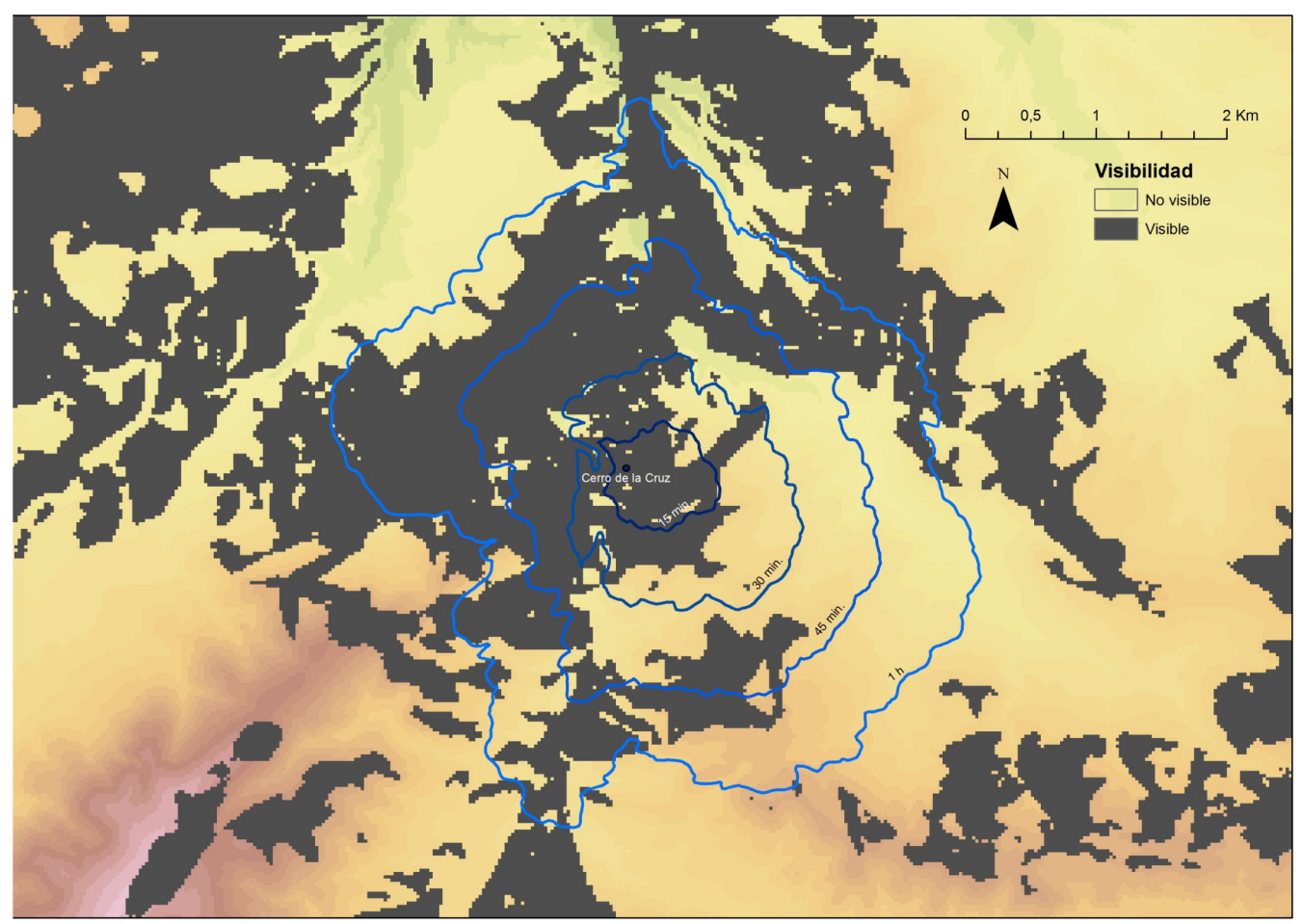

Figura 7. Imagen que muestra el área visible desde el Cerro de la Cruz (color gris) y la superposición de las isócronas de 15, 30, 45 y 60 minutos de distancia al yacimiento.

Para realizar el análisis estadístico de los datos, cuantificamos la superficie visible y la no visible en cada uno de los anillos de distancia en torno al asentamiento. Para ello utilizamos la herramienta Extract by mask, que permite hacer recortes con un polígono (las isócronas) sobre superficies raster (el viewshed). Una vez obtenidas las nuevas raster (áreas de visibilidad/no visibilidad comprendidas dentro de cada una de las isócronas), procedimos al análisis del número de celdillas visibles y no visibles contenido en cada una de ellas (Figura 8). Los resultados, expresados en hectáreas de terreno, fueron los siguientes:

En un área circular de $3 \mathrm{~km}$ a la redonda:

- existen 1335 Ha de superficie visible y 1492 Ha de superficie no visible desde el yacimiento.

- De esas 1492 Ha no visibles, algo más de la mitad (756 Ha) están a más de 1 hora caminando desde el yacimiento. Estas zonas se reparten hacia la mitad oeste y hacia el Norte-Noreste del área circular de $3 \mathrm{~km}$, más allá de la isócrona de $1 \mathrm{~h}$.

- Un $49 \%$ de la superficie no visible $(736 \mathrm{Ha})$ se localiza a menos de 1 hora del yacimiento, sobre todo en la zona al Este, Sureste y Sur del mismo (Tabla 1).

- Más de la mitad de la superficie no visible a menos de 1 hora se concentra entre 45 minutos y 1 hora de distancia (Tabla 2).

- Aproximadamente a un $15 \%$ de la superficie no visible se tendría acceso en menos de media hora desde el yacimiento. 


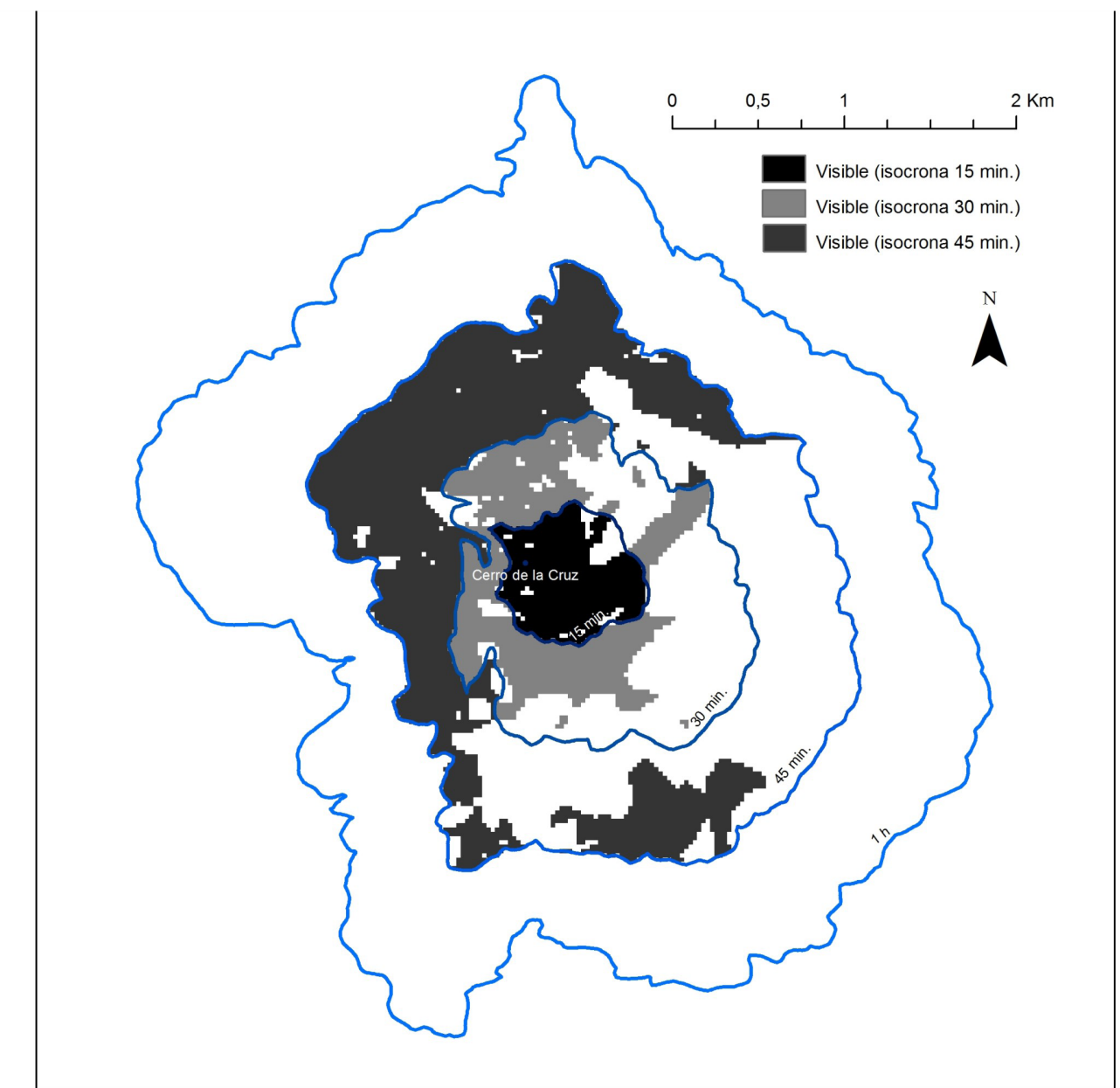

Figura 8. Isocronas de distancia en torno al Cerro de la Cruz (líneas en azul) con el área de visibilidad comprendida entre cada una de ellas (hasta la de 45 minutos). El hecho de separar individualmente la capa de visibilidad en capas diferentes en función de la distancia al yacimiento nos permite averiguar el porcentaje de terreno 'visible' y 'no visible' desde el yacimiento en cada uno de los sectores de distancia considerados (atendiendo a los datos que cada capa contiene en su correspondiente tabla de atributos).

\begin{tabular}{|l|l|l|l|l|l|}
\hline & $\begin{array}{l}\text { buffer 3 } \\
\mathrm{km}\end{array}$ & $\begin{array}{l}\text { A menos } \\
\text { de } 1 \mathrm{~h}\end{array}$ & $\begin{array}{l}\text { A menos } \\
\text { de 45' }\end{array}$ & $\begin{array}{l}\text { A menos } \\
\text { de 30' }\end{array}$ & $\begin{array}{l}\text { A menos } \\
\text { de 15' }\end{array}$ \\
\hline $\begin{array}{l}\text { Hectáreas No } \\
\text { visibles }\end{array}$ & 1492,4375 & 736 & 333,5 & 115,4375 & 5,6875 \\
\hline Hectáreas Visibles & 1335,3125 & 874,0625 & 403,0625 & 143,3125 & 46,5625 \\
\hline
\end{tabular}

Tabla 1. Número de Hectáreas de terreno visibles y no visibles según distancias

\begin{tabular}{|l|l|l|l|l|l|}
\hline & $\begin{array}{l}\text { A menos } \\
\text { de 1 h }\end{array}$ & $\begin{array}{l}\text { Entre 45' } \\
\text { v 1 h }\end{array}$ & $\begin{array}{l}\text { Entre 30'- } \\
45^{\prime}\end{array}$ & $\begin{array}{l}\text { Entre } \\
15^{\prime} 30^{\prime}\end{array}$ & $\begin{array}{l}\text { A menos } \\
\text { de 15' }\end{array}$ \\
\hline No visible $(\mathrm{Ha})$ & 736 & 402,5 & 218,0625 & 109,75 & 5,6875 \\
\hline $\begin{array}{l}\text { \% sobre el total de } \\
\text { Ha }\end{array}$ & $100 \%$ & $54,68 \%$ & $29,62 \%$ & $14,91 \%$ & $0,77 \%$ \\
\hline
\end{tabular}

Tabla 2. Número y porcentaje de Hectáreas (Ha) de terreno 'No visible' comprendidas en cada uno de los anilos de distancia temporal considerados 


\section{Discusión y conclusiones}

Este tipo de análisis deberá ser ampliado más adelante a zonas más lejanas en torno al Cerro de la Cruz, en especial a fin de valorar la distancia a recorrer para alcanzar determinados enclaves del paisaje que se encuentran dentro del radio de alcance visual del poblado (por ejemplo, otros asentamientos con los que presenta intervisibilidad).

Pero aunque es interesante valorar si las áreas inaccesibles a la vista lo son también (y en qué grado) desplazándose por el terreno, es obvio que deberíamos tener en cuenta en qué momento y lugar a lo largo de ese desplazamiento se produce una nueva ampliación del área visible (que cambiaría, por tanto, la inicial cualidad de 'no visible' de algunas zonas).

Se trata de un asunto rico y complejo, que alude al dinamismo de la vida en los paisajes y de las particularidades de los contextos en los que la visibilidad del medio resultaba relevante ${ }^{7}$. La capacidad del observador de moverse por el paisaje y cambiar así su campo visual cuestiona el resultado del cálculo de visibilidad cuando se realiza desde un único punto de observación (Bermúdez 2000: 482; Martín de la Cruz et al. 2004: 219). Ello ha sido estudiado dentro de ámbitos como el de la seguridad vial, atendiendo al mejor lugar en el que situar señales de tráfico (Felleman 1986b: 55), y a menudo es analizado, también en el ámbito de la arqueología, por medio de la suma de varias áreas de visibilidad obtenidas desde puntos de observación espaciados, por ejemplo, a lo largo de un camino (Felleman 1986b: 60; Bell y Lock 2000), o considerando como lugar de observación no sólo la superficie del yacimiento sino también los cerros próximos (Zamora 2006a).

Estas reflexiones nos llevan a reparar, una vez más, en ya antiguos planteamientos, propuestas para mejorar el resultado final del cálculo haciéndolo menos rígido y más acorde con la visibilidad real, que siguen estando de actualidad. Nos referimos a conceptos como 'probable viewshed' y fuzzy viewshed (Fisher 1992, 1993, 1994).

En relación a cuestiones de la informática, la comparación de diferente software calculando la visibilidad desde un mismo punto, así como con diferentes MDTs, y sus resultados dispares, llevó a Fisher a la creación del llamado 'probable viewshed' como modo de mejorar lo inapropiado de la representación binaria del cálculo de visibilidad. Se trata de una simulación que, introduciendo posibles variantes en los algoritmos de cálculo del MDT (previamente conocidos), genera tantos cálculos de visibilidad como variantes, de modo que los valores normales de 0 y 1 que deberían indicar las celdillas según fueran invisibles o no estarían entre 0 y el número total de variantes realizadas, con lo cual se obtendría un área de visibilidad menos errónea cuanto mayor sea el número de variantes introducidas (Fisher 1992, 1993).

El concepto en sí ya aparecía al menos en 1986 en palabras de Felleman, quien para solventar la incertidumbre que el potencial bloqueo de la cubierta vegetal introduce en el resultado del cálculo de visibilidad proponía realizar tres cálculos diferentes: el primero añadiendo al cálculo la altura máxima que pudiera tener la vegetación potencial, en otro la altura mínima y en el tercero la media. El resultado sería un mapa que indicara no sólo las categorías de visible e invisible sino también una tercera categoría de visibilidad ambigua (Felleman 1986b:61).

A fin de paliar la incertidumbre producida por las variaciones de las condiciones atmosféricas, se han realizado también algunas propuestas. Fisher elaboró un algoritmo que calculaba fuzzy viewshed en función de la existencia de neblina y de la refracción del sol a través 
de ella, que hacía disminuir la visibilidad más acusadamente hacia la dirección del sol, pero el mismo autor convino en admitir la dificultad existente en definir los parámetros ya que sus magnitudes dependen de la clase de objetivos que son observados, entre otros aspectos (Fisher 1994). En base a observaciones de campo en el yacimiento de Alhonoz (Sevilla), realizamos algunas reflexiones e interpretaciones acerca de las particularidades topoclimáticas de cada zona de estudio en relación con posibles redes de comunicación visual entre asentamientos que podrían quedar interrumpidas según épocas del año (Zamora 2002, 2004, 2006a, 2010a).

En algunos de los trabajos en los que se han propuesto mejoras cualitativas en el cálculo de visibilidad, se ha comentado la dificultad de introducir variantes en los algoritmos de cálculo (Fisher 1992: 351). Lo que hemos planteado en este trabajo en relación con la visibilidad desde el asentamiento y la distancia a las zonas no visibles es una aproximación cualitativa sin pretender introducir variaciones en el algoritmo de cálculo.

La cualificación del territorio en 'visible' y 'no visible' de cara a averiguar el grado de control visual desde el yacimiento (conocimiento de lo que está ocurriendo en el territorio) queda más completa y realista si se considera el grado de accesibilidad de las zonas ocultas.

Las figuras 7 y 8 muestran el resultado del cálculo de visibilidad en torno al Cerro de la Cruz de Almedinilla con la superposición de las líneas isócronas de distancia al yacimiento. La imagen resultante aporta una mayor cantidad de información sobre las características de esos espacios vistos y ocultos, permitiendo al investigador una mejor valoración del espacio en torno al asentamiento.

En este artículo hemos reflexionado acerca de algunos aspectos metodológicos y de contenido histórico relativos al estudio de la visibilidad del paisaje en Arqueología. Hemos valorado el significado de la expresión 'control visual', así como hecho hincapié en la importancia que la lectura de los textos de los autores clásicos tiene en relación con la contextualización del ejercicio de la visibilidad durante la Antigüedad.

De igual manera, hemos valorado el contexto de la disponibilidad cartográfica hoy en España, fundamental para emprender cualquier tipo de análisis SIG territorial, y reflexionado sobre la incertidumbre que los datos cartográficos de partida o la dificultad de modelar digitalmente la realidad sensorial, pueden estar aportando al estudio de la visibilidad paisajística mediante SIG.

Por último, hemos mostrado la utilidad y conveniencia de asociar distintos tipos de herramientas ofrecidas por los programas SIG, como viewshed y path distance, para obtener análisis del territorio más completos, incidiendo también en la conveniencia de la exploración estadística de los resultados del cálculo de visibilidad, como modo de cuantificar de alguna manera un aspecto tan fundamentalmente humano como es el de la percepción visual del territorio.

\section{Notas}

1. Este trabajo se enmarca en la Unidad Asociada UAM-CSIC Ana et Tagum (ANTA), formada por el Dpto. Prehistoria y Arqueología de las Universidad Autónoma de Madrid (UAM) y por el Instituto de Arqueología del Consejo Superior de Investigaciones Científicas (CSIC), y dentro de su línea de investigación en Estudios del territorio a través de las nuevas metodologías. 
2 Por ejemplo, la primera y más obvia objeción al cálculo informático de visibilidad que se suele plantear es la de no considerar el posible bloqueo que la vegetación arbórea pudiese estar ocasionando (Chapman y Gearey 2000; Tschan et al. 2000; Wheatley y Gillings 2000, 2002; Gillings y Wheatley 2001: 32-33; Llobera 2007). Una recopilación, ya algo antigua, de la discusión y soluciones planteadas por diversos autores sobre ésta y otras deficiencias del cálculo de visibilidad también en Zamora 2006a: 11 y ss. y en sus capítulos específicos. 3 “... sin que lo advirtieran los centinelas, que en la oscuridad no los veian ante sí ni tampoco los oían debido a que el fragor del viento apagaba el ruido que hacian los plateos al avanzar; éstos marchaban, además, manteniéndose a una gran distancia para evitar que las armas se entrechocaran y dieran la alerta" (Thuc. III,22,1); “(...) y, cuando, durante la noche, se dé la señal con una trompeta” (Aen. Tact. IX,1); "Durante las oscuras noches de invierno (...) El mejor plan, en tales noches, es atar perros fuera de la muralla hasta que se haga de día; los animales descubrirán, desde una distancia mayor, al espía de los enemigos, al desertor que se aproxima sigilosamente a la ciudad o al que, en alguna parte, se dispone a desertar. Al mismo tiempo, despertarán con sus ladridos al guardia que haya podido dormirse." (Aen. Tact. XXII,12).

4 "Los guardias diurnos han de ser también veloces para que puedan llegar enseguida y comunicar el mensaje desde la mayor distancia posible, en aquellas circunstancias en las que no resulte posible transmitir las señales pero sea imprescindible que alguno de ellos lleve el mensaje." (Aen. Tact. $\mathrm{VI}, 5)$; "Cuando se disponga de caballería y el terreno sea propicio, es mucho mejor disponer relevos de jinete, para transmitir los mensajes con mayor celeridad." (Aen. Tact. VI,6).

5 Proyecto: "Estudio arqueológico de la comarca de Almedinilla (Córdoba)", Convenio Universidad Autónoma de Madrid, Ayuntamiento de Almedinilla (Córdoba).

6 Cartografía de base: Mapa Vectorial de Andalucía a escala 1:10.000, Instituto de Cartografía de Andalucía.

7 Eneas el Táctico (Aen. Tact. VI,1): "Hay que estacionar también delante de la ciudad guardias diurnos en un lugar elevado y visible desde la mayor distancia posible", (VI,4): "Si no se cuenta con unos emplazamientos desde los que se puedan enviar señales a la ciudad, deben situarse en diferentes puntos puestos de transmisión para que hagan llegar a la ciudad las señales recibidas" y $(\mathrm{XV}, 5)$ : "No obstante, es preciso que, en primer lugar, salgan en avanzadilla la caballería y la infantería ligera disponibles, también en orden, con la misión de rastrear el terreno y de ocupar las posiciones elevadas, a fin de que los hoplitas conozcan con la mayor antelación los planes de los enemigos y no sufran un ataque por sorpresa". Sobre construcción de elevaciones improvisadas allí donde fuera más necesario: "Debe ser alzada (la linterna) desde un lugar que sea visible a todos los guardias de la muralla. En el caso de que no exista tal lugar, debe prepararse, con cualquier material, una elevación lo más alta posible." (Aen. Tact. XXVI,13 y otra referencia similar en XL,1). También Suetonio (Tib. 65,2): “... y desde una roca muy elevada acechaba continuamente las señales que había ordenado levantar a lo lejos".

\section{Bibliografía citada}

Autores antiguos

Eneas el Táctico, Poliorcética, Biblioteca Clásica Gredos, 157, Editorial Gredos, Madrid, 1991, Introducción, traducción y notas de José Vela Tejada y Francisco Martín García, pp. 7-143.

Tucídices, Historia de la Guerra del Peloponeso, Libros III y IV, Biblioteca Clásica Gredos, 151, Madrid, 1991, traducción y notas de J.J. Torres Esbarranch.

Suetonio, Vidas de los doce Césares, Libros I-III, Biblioteca Clásica Gredos, 167, Madrid, 1992, Introducción general de Antonio Ramírez de Verger, Traducción de Rosa Mª Agudo Cubas. 
Autores modernos

Allepuz Marzà, X.

2001 Introduccióal poblament ibèric a la plana del'Arc(Castelló), Diputació deCastelló, Collecció Universitària.

Baena Preysler, J.

2003 La Arqueología peninsular y los SIG: presente y futuro. Arqueoweb, Revista sobre Arqueología en Internet 5 (1).

Baena, J., Blasco, C. y V. Recuero

1995 The spatial analysis of Bell Beaker sites in the Madrid region of Spain. Archaeology and Geographical Information Systems: A European Perspective (ed. por G. Lock y Z. Stanciî̂), pp. 101-116. Taylor \& Francis, Londres.

Bell, T.

1999 Reconstructing Archaeology from the Landscape: GIS, CAD and the Roman Signal Station at Whitby. Archaeology in the Age of the Internet: Computer Applications and quantitative Methods in Archaeology CAA97 (ed. por L. Dingwall, S. Exon, V. Gaffley, S. Laflin y M. Van Leusen). BAR International Series 750, Oxford.

Bermúdez Sánchez, J.

2000 La aplicación de los Sistemas de Información Geográfica a la Arqueología. Tesis de Doctorado, Universidad Autónoma de Madrid, Madrid.

Berrocal, M.C.

2004 La investigación del arte rupestre desde la geografía: la pintura neolítica del ámbito mediterráneo de la Península Ibérica. Trabajos de Prehistoria 61(2): 41-62.

Berrocal Rangel, L.

2004 La defensa de la comunidad: sobre las funciones emblemáticas de las murallas protohistóricas en la Península Ibérica. Gladius XXIV: 27-98.

Burillo Mozota, F.

1980 El valle medio del Ebro en época ibérica. Contribución a su estudio en los ríos Huerva y Jiloca Medio. Institución "Fernando el Católico", Zaragoza.

Cara Barrionuevo, L. y J.M. Rodríguez López

1984 Análisis de distribución espacial de las comunidades megalíticas en el valle del río Andarax (Almería). Arqueología Espacial. Coloquio sobre distribución y relaciones entre los asentamientos, 27-29 de septiembre de 1984, Tomo 3, Del Epipaleolítico al Bronce Medio, Seminario de Arqueología y Etnología Turolense, Colegio Universitario de Teruel, pp. 53-75.

Chapman, H. P. y B.R. Gearey

2000 Paleoecology and the perception of prehistoric landscapes: some comments on visual approaches to phenomenology. Antiquity 74: 316-319.

Constantinidis, D.

2004 The Interconnectivity of Cultural Sites: Sights and Sounds across a Landscape. Enter the Past. The E-way into the Four Dimensions of Cultural Heritage, CAA2003, Computer Applications and Quantitative Methods in Archaeology, pp. 258-262. Proceedings of the 31st Conference, Vienna, Austria, April 2003, BAR International Series, 1227, Oxford. 
Felleman, J.P.

1986 Landscape visibility. Foundations for visual project analysis (ed. por R.C. Smardon, J.F. Palmer y J.P. Felleman), pp. 47-62. John Wiley \& Sons, Nueva York.

Fisher, P.F.

1991 First Experiments in Viewshed Uncertainty: The Accuracy of the Viewshed Area. Photogrammetric Engineering \& Remote Sensing 57(10): 1321-1327.

1992 First Experiments in Viewshed Uncertainty: Simulating Fuzzy Viewsheds. Photogrammetric Engineering \& Remote Sensing 58(3): 345-352.

1993 Algorithm and implementation uncertainty in viewshed analysis. International Journal of Geographical information Systems 7(4): 331-347.

1994 Probable and fuzzy models of the viewshed operation. Innovation in GIS, selected papers from the First National Conference on GIS Research UK (Ed. M.F. Worboys), pp. 161-175. Taylor \& Francis,

Fraser, D.

1983 Land and Society in Neolithic Orkney. British Archaeological Reports, 117, Oxford.

1988 The orientation of visibility from the chambered cairns of Eday, Orkney. Records in Stone (ed. por C. Ruggles), pp. 325-336. Cambridge University Press, Cambridge.

García Rincón, J.M.

1987 Aproximación al estudio espacial del área de Tejada la Vieja. Tejada la Vieja: Una ciudad protohistórica (ed. por J. Fernández Jurado), Huelva Arqueológica, IX, pp. 189-219. Excma. Diputación Provincial de Huelva.

García Sanjuán, L.

1999 Los orígenes de la estratificación social: patrones de desigualdad en la Edad del Bronce del Suroeste de la Península Ibérica (Sierra Morena Occidental c. 1700-1100 a.n.e. /2100-1300 a.n.e.). BAR International Series 823, Oxford.

Gillings, M. y D. Wheatley

2001 Seeing is not believing. Unresolved issues in archaeological visibility analysis. On the good use of geographic information systems in archaeological landscape sutdies (ed. por B. Slapšak), pp- 25-36. COST Action G2 Ancient Landscapes and Rural Structures, Proceedings of the COST G2 WG2 round table, Ljubljana.

Grau Mira, I.

1998 Aproximación al territorio de época ibérica plena (ss. IV-II aC) en la región centro meridional del País Valenciano. Arqueología Espacial 19-20: 309-321.

2001 GIS tools to analyze the Iberian Iron Age landscape in Eastern Spain. Archaeological Computing Newsletter 57: 1-5.

2002a La organización del territorio en el área central de la Contestania Ibérica. Universidad de Alicante. $2002 b$ GIS approach to Iberian Iron Age landscape in central-south Valencia region (Spain). Archaeological Informatics: Pushing the Envelope, CAA 2001, Computer Applications and Quantitative Methods in Archaeology (ed. por G. Burenhult), pp. 43-47. Proceedings of the 29th Conference, Gotland, April 2001, BAR International Series 1016, Oxford.

$2005 \mathrm{El}$ territorio septentrional de la Contestania. La Contestania Ibérica, treinta años después (ed. por L. Abad, F. Sala e I. Grau), pp. 73-90. Publicaciones de la Universidad de Alicante, Serie Arqueología, Alicante. 
Grau Mira, I. y J. Molina Hernández

2005 La organización de un valle de la Contestania: La Vall de Seta en época ibérica. $L a$ Contestania Ibérica, treinta años después (ed. por L. Abad, F. Sala e I. Grau), pp. 243-255. Publicaciones de la Universidad de Alicante, Serie Arqueología, Alicante.

Junyent, E.

1991 Contribució al coneixement de les estructures defensives en els assentaments de la Catalunya occidental. Bronze Final, Primera Edat del Ferroi època ibèrica. Estat de la qüestió. Actas del Simposi Internacional d'Arqueologia Ibèrica, pp. 103-108. Manresa, 6-9 diciembre, Publicacions del Centre d'Estudis del Bages, sèrie «Actes».

Keay, S.J., Wheatley, D. y S. Poppy

2001 The territory of Carmona during the Turdetanian and Roman periods: some preliminary notes about visibility and urban location. Carmona romana (ed. por A. Caballos), pp.397-412. Actas del II Congreso de Historia de Carmona, Carmona (Sevilla).

Kvamme, K.L.

1990 GIS algorithms and their effects on regional archaeological analysis. Interpreting space: GIS and archaeology (ed. por K.M. Allen, S.W. Green y E.B. Zubrow), pp. 112-125. Taylor \& Francis, London, New York, Philadelphia.

Lock, G.R. y T.M. Harris

1996 Danebury revisited: an English Iron Age hillfort in a digital landscape. Anthropology, Space and Geographic Information Systems (ed. por M. Aldenderfer y H.D. Maschner), pp. 214240. Oxford University Press, Oxford, New York.

Llobera, M.

1996 Exploring the topography of mind: GIS, social space and archaeology. Antiquity 70: 612-622. 2007 Modeling visibility through vegetation. International Journal of Geographical Information Science 21(7): 799-810.

Llobera, M., Fábrega-Álvarez, P. y C. Parcero-Oubiña

2011 Order in movement: a GIS approach to accessibility. Journal of Archaeological Science 38: 843-851.

Marozas, B.A. y J.A. Zack

1990 GIS and archaeological site location. Interpreting Space: GIS and Archaeology (ed. por K.M. Allen, S.W. Green y E.B. Zubrow), pp. 165-172. Tayor \& Francis, London, New York, Philadelphia.

Martín de la Cruz, J.C., Bermúdez Sánchez, J. y M.R. Perlines Benito

2004 Los Sistemas de Información Geográfica aplicados a la campiña de Córdoba: sincronías y diacronías poblacionales. Actas del I Encuentro Internacional Informática Aplicada a la Investigación y la Gestión Arqueológicas, pp. 211-235 más figuras en Cdrom. Servicio de Publicaciones, Universidad de Córdoba, Córdoba.

Montilla, S., Risquez, C., Serrano, J.L. y B.E. Coba

1989 Análisis de una frontera durante el horizonte ibérico en la depresión Priego-Alcaudete. en Burillo F. (ed.): Fronteras, Arqueología Espacial, 13, Teruel, pp. 137-149. 
Muñiz Jaén, I. y F. Quesada Sanz (eds.)

2010 Un drama en tres actos. Dos milenios de ocupación humana en el Cerro de la Cruz (Almedinilla, Córdoba). Oikos, Cuadernos Monográficos del Ecomuseo del río Caicena, $\mathrm{n}^{\circ} 2$. Publicación del Ecomuseo del Río Caicena. Excmo. Ayuntamiento de Almedinilla, Córdoba.

Murillo, J.F., Quesada, F., Vaquerizo, D., Carrillo, J.R. y J.A. Morena

1989 Aproximación al estudio del poblamiento protohistórico en el sureste de Córdoba: unidades políticas, control del territorio y fronteras. Arqueología Espacial 13: 151-172.

Murrieta-Flores, P.

2012 Understanding human movement through spatial technologies. The role of natural areas of transit in the Late Prehistory of South-western Iberia. Trabajos de Prehistoria 69(1): 103-122.

Novaković, P.

2001 Detecting territoriality and social structure in the Bronze and Iron Ages. On the good use of geographic iformation systems in archaeological landscape studies (ed. por B. Slapšak), pp. 101-115. Proceedings of the COST G2 WG2 round table, Ljubljana, 18 to 20 December 1998.

Ortega Alba, F.

1975 El sur de Córdoba. Estudio de Geografía agraria, Publicaciones del Monte de Piedad y Caja de Ahorros de Córdoba, Córdoba, 2 Vols.

Pérez Verbena, J.

2000 Potencialidad agrícola y estrategia defensiva: Un binomio estructurado en el Rincón de Ademuz durante el Ibérico Pleno. III Reunió sobre Economia en el Món Ibèric. SAGVNTVMPLAV, Extra-3: 109-114.

Ramos Muñoz, J. y A.J. Moreno Araguez

1984 El poblamiento humano calcolítico en la presa de la Viñuela (Málaga). Arqueología Espacial. Coloquio sobre distribución y relaciones entre los asentamientos, 27-29 de septiembre de 1984, Tomo 3, Del Epipaleolítico al Bronce Medio, Seminario de Arqueología y Etnología Turolense, Colegio Universitario de Teruel, pp. 157-174.

Renfrew, C.

1979 Investigations in Orkney. The Society of Antiquaries of London, Londres.

Rodríguez Traver, J.A. y J. Pérez Ballester

2005 El poblamiento ibérico antiguo en el valle del río Cànyoles (La Costera, Valencia). La Contestania Ibérica, treinta años después (ed. por L. Abad, F. Sala e I. Grau), pp. 211-225., Publicaciones de la Universidad de Alicante, Serie Arqueología, Alicante.

Ruestes, C.

2006 El poblamiento ibérico y romano en la Layetania litoral (del río Besòs a la riera de Teià). La Aplicación de los SIG en la Arqueología del Paisaje (ed. por I. Grau), pp. 227-246. Universidad de Alicante, Alicante.

Ruíz Rodríguez, A.

1990 Reflexiones sobre algunos conceptos de arqueología espacial a partir de una experiencia: Iberos en el alto Guadalquivir. Arqueología Espacial 12: 157-172. 
Ruíz, A. y M. Molinos

1993 Los iberos. Análisis arqueológico de un proceso histórico. Ed. Crítica, Barcelona.

Ruíz, A., Molinos, M. y C. Choclán

1991 Fortificaciones ibéricas en la alta Andalucía. Fortificacions. Simposi Internacional d'Arqueologia Ibèrica, pp. 109-126. Manresa, 6-9 de diciembre de 1990, Publicacions del Centre d'Estudis del Bages, sèrie Actes.

Sáenz de Urturi, F.

1984 Relaciones entre asentamientos de la Edad del Hierro y época romana en el valle de Valdegobia (Álava). Arqueología Espacial. Coloquio sobre distribución y relaciones entre los asentamientos, 27-29 de septiembre de 1984, Tomo 2, Estudios diacrónicos y Paleolítico, Seminario de Arqueología y Etnología Turolense, Colegio Universitario de Teruel, pp.7-19.

Slapšak, B.

1988 Defining the Economic Space of a Typical Iron Age Hillfort: Rodik (Yugoslavia). A Casestudy. Conceptual Issues In Environmental Archaeology (ed. por J.L. Bintliff, D.A. Davidson y E.G. Grant), pp. 95-107. Edinburgh University Press, Edimburgo.

Stanĉîc, Z.

1994 Locational analysis and settlement studies with GIS. Methods in the Mountains (ed. por I. Johnson), pp. 73-79. Proceedings of UISPP Commission IV Meeting, Mount Victoria, Australia, August 1993, Sydney University, Archaeological Methods Series 2, Sydney.

Swanson, S.

2003 Documenting Prehistoric Communication Networks: a case study in the Paquimé Polity. American Antiquity 68(4): 753-767.

Tobler, W.

1993 Three presentations on Geographical Analysis and Modelling: 1) Non-isotropic modelling 2) Speculations on the geometry of geography 3) Global spatial analysis" http:// www.ncgia.ucsb.edu/Publications/Tech_Reports/93/93-1.PDF

Tschan, A.P., Raczkowski, Q. y M. Latalowa

2000 Perception and viewsheds: are they mutyally inclusive? Beyond the Map: Archaeology and Spatial Technologies (ed. por G. Lock), pp. 28-48. IOS Press, Amsterdam.

Topouzi, S., Sarris, A., Pikoulas, Y., Mertikas, S., Frantzis, X. y A. Giourou 2002 Ancient Mantineia's Defence Network Reconsidered Through a GIS Approach. Archaeological Informatics: Pushing the Envelope, CAA 2001, Computer Applications and Quantitative Methods in Archaeology (ed. por G. Burenhult), pp. 559-566. Proceedings of the 29th Conference, Gotland, April 2001, BAR International Series 1016, Oxford.

Vaquerizo Gil, D.

1987 Aproximación a la arqueología en la Subbética cordobesa. Revista de Arqueología 77: 10-19.

Vaquerizo, D., Murillo, J.F. y F. Quesada

1991 Avance de la prospección arqueológica de la Subbética cordobesa: la depresión de Priego-Alcaudete. Anales de Arqueología Cordobesa 2: 117-170. 
Vaquerizo Gil, D., Quesada Sanz, F. y J.F. Murillo Redondo

2001 Protohistoria y romanización en la Subbética Cordobesa. Una aproximación al desarrollo de la cultura ibérica en el sur de la actual provincia de Córdoba. Junta de Andalucía, Universidad de Córdoba, Córdoba.

Wheatley, D.

2000 Spatial technology and archaeological theory revisited. CAA96. Computer Applications and Quantitative Methods in Archaeology (ed. por K. Lockyear, T.J. Sly y V. Mihăilescu-Bîrliba), pp. 123-131. BAR International Series 845, Oxford.

Wheatley, D. y M. Gillings

2000 Vision, perception and GIS: developing enriched approaches to the study of archaeological visibility. Beyond the Map: Archaeology and Spatial Technologies (ed. por G. Lock), pp. 1-27. IOS Press, Amsterdam.

Zamora Merchán, M.

2002 Computerised and real viewsheds. An example from the Genil River valley, Southern Spain. Archaeological Computing Newsletter 58: 7-10.

2004 Viewshed variations throughout the year at the Alhonoz site (Seville, Spain) and its implications on the local communication network. Enter the Past, The E-way into the Four Dimensions of Cultural Heritage, CAA 2003, Computer Applications and Quantitative Methods in Archaeology 2003, Vienna (Austria). BAR International Series 1227, Oxford. Abstract en Cdrom.

2006a Territorio y espacio en la Protohistoria de la Península Ibérica. Estudios de visibilidad: el caso de la cuenca del Genil, Tesis Doctorales, Ediciones de la Universidad Autónoma de Madrid, Libro electrónico en Pdf, Madrid.

2006b Visibilidad y SIG en Arqueología: mucho más que ceros y unos. La aplicación de los SIG a la Arqueología del Paisaje (ed. por I. Grau), pp.41-54. Publicaciones de la Universidad de Alicante, Alicante. 2007 Total and Cumulative viewshed: an Application in the Genil River Valley. The world is in your eyes - Proceedings of the XXXIII Computer Applications in Archaeology (ed. por A. Figueiredo y G. Leite Velho), pp. 313.318. Conference Tomar March 2005, Tomar (Portugal). 2010a Topoclimatic Models and Viewshed. Beyond the Artifact. Digital interpretation of the Past (ed. por F. Niccolucci y S. Hermon), pp. 232-236. Proceedings of CAA2004, Computer Applications and Quantitative Methods in Archaeology Conference 2004, Prato (Italia), Archaeolingua, Budapest. $2010 \mathrm{~b}$ El territorio y el poblado del Cerro de la Cruz. Un drama en tres actos. Dos milenios de ocupación humana en el Cerro de la Cruz (Almedinilla, Córdoba) (ed. por I. Muñiz Jaén y F. Quesada Sanz), pp. 49-65. Oikos, Cuadernos monográficos del Ecomuseo del río Caicena, $\mathrm{n}^{\circ} 2$. Publicación del Ecomuseo del Río Caicena. Excmo. Ayuntamiento de Almedinilla, Córdoba. 2011 Cálculos de visibilidad en arqueología: La visibilidad del territorio desglosada en ángulos verticales y su aplicación al período ibérico tardío de Andalucía central. Actas del V Simposio Internacional de Arqueología de Mérida: Los SIG y el análisis arqueológico del territorio, Noviembre 2007, Mérida, Consejo Superior de Investigaciones Científicas, Instituto de Arqueología. Anejos Archivo Español de Arqueología LIX: 309-323, publicación en Cd-ROM. 2012 Improving methods for viewshed studies in Archaeology: the vertical angle. Actas del congreso On the Road to Reconstructing the Past, Computer Applications and Quantitative Methods in Archaeology 2008, Budapest, 2-6 abril 2008, Archaeolingua, Budapest, Paper en Cdrom.

Zamora Merchán, M. y J. Baena Preysler

2010 Los SIG en la Arqueología española: una valoración 'CAA' del contexto actual. Cuadernos de Prehistoria y Arqueología de la Universidad de Granada 20: 49-64. 